\title{
Correspondence
}

\section{Caspase 14 does not influence intestinal epithelial cell differentiation}

\author{
Cell Death and Differentiation (2013) 20, 524; doi:10.1038/cdd.2012.164; published online 4 January 2013
}

\section{Dear Editor}

Caspase 14 is unique among the caspases by being expressed only in epithelia of terrestrial animals, and further to be involved in cellular differentiation rather than cell death or inflammation. ${ }^{1,2}$ Caspase 14 has been investigated mainly in cornifying epithelia, where it is solely expressed in differentiating, nondividing keratinocytes, and is involved in the processing of structural proteins. ${ }^{3}$ Caspase 14 has also been associated with other epithelium-derived systems and is proposed have tumor-suppressor effects in breast cancer cells. ${ }^{4}$ It was therefore of interest when it was reported in Cell Death \& Differentiation that caspase 14 is expressed in intestinal epithelial cells, ${ }^{5}$ a finding that was later confirmed by others who found expression of caspase 14 in nonneoplastic mucosa as well as in intestinal neoplastic cells. ${ }^{6}$

Incidentally, we found evidence of high expression levels of caspase 14 mRNA in a gene array expression analysis (HS002N; SuperArray Bioscience, Bethesda, MD, USA) performed on isolated human primary colonic epithelial cells. ${ }^{7}$ To further investigate the role of caspase 14, we isolated human colonic epithelial cells and grew them on different basal membrane constituents (collagen, tenascin c, and laminin) known to influence epithelial cell differentiation. ${ }^{8}$ We investigated whether caspase 14 was cleaved and activated like other caspases in detachment-induced apoptosis. We also examined whether the expression pattern of caspase 14 was affected by colonic epithelial cell differentiation in Caco2 cells. Finally, we assessed the expression in selected colon cancer cell lines (HT-29, DLD1, and Caco2 as mentioned).

We did indeed find expression of a $30-\mathrm{kD}$ protein with an antibody to detect caspase 14 used by various other research groups (H99, rabbit polyclonal, Santa Cruz Biotechnology, Heidelberg, Germany). There was no sign of cleavage of this band during basal membrane constituent stimulation- or detachment-induced apoptosis. However, colon cancer cell lines did have both a $30-$ and a $20-\mathrm{kDa}$ band, suggesting constitutive activation of caspase 14 in these cells. Immunohistochemistry showed an increased expression along the crypt axis with maximal expression in the upper third of the crypt, suggesting that the protein expression depended on the level of epithelial cell differentiation (see Supplementary Figure).

However, subsequent attempts to confirm the results by PCR were fruitless. Although we did find high levels of expression in human skin, no expression was detectable in the intestinal cells mentioned, including neoplastic cells and differentiated Caco2 cells in spite of the use of several primer sets covering both the $5^{\prime}$ end, the middle part, and $3^{\prime}$ end of the mRNA (see Supplementary Figure). Lately, while working on another project using the cap analysis gene expression, we could definitely conclude that human primary intestinal epithelial cells do not express caspase 14 or truncated caspase 14 mRNA. The H99 antibodies therefore detect unspecific bands at the 30- and 20$\mathrm{kDa}$ positions where caspase 14 is expected to be found. We contacted the manufacturer of the array system used in our lab to for the initial identification of caspase 14, but they were unwilling to share their caspase 14 sequences with us to address the specificity of the array.

We therefore conclude that caspase 14 does neither affect the differentiation of intestinal epithelial cells nor colon cancer cell development. Further, we suggest that one should be careful with the interpretation of reports on involvement of caspase 14 in other cells than cornifying cells, as they are largely based on the methods reported here. In general, identification of proteins should be supported by including proper positive and negative controls both on the mRNA level and the protein level to avoid publication of false-positive results.

\section{Conflict of interest}

The authors declare no conflict of interest.

\footnotetext{
J Benedict Seidelin ${ }^{*, 1}$, J Sträter ${ }^{2}$ and O Haagen Nielsen ${ }^{3}$

${ }^{1}$ Department of Internal Medicine, Bispebjerg Hospital, University of Copenhagen, Herlev, Denmark;

2 Institute of Pathology, Klinikum Esslingen, Esslingen, Germany and

3 Department of Gastroenterology, Medical Section, Herlev Hospital, University of Copenhagen, Herlev, Denmark

* Corresponding authors: JB Seidelin, Department of Gastroenterology, Medical Section, Herlev Hospital, Herlev Ringvej 75, DK-2730 Herlev, Denmark.

Tel: + 45386836 21; Fax: + 45386840 09;

E-mail: jseidelin@dadlnet.dk

1. Denecker $\mathrm{G}$ et al. J Cell Biol 2008; 180 : 451-458

2. Denecker $\mathrm{G}$ et al. Nat Cell Biol 2007; 9: 666-674.

3. Hoste $\mathrm{E}$ et al. J Invest Dermatol 2011; 131: 2233-2241.

4. Asselin-Labat ML et al. Mol Cell Biol 2011; 31: 4609-4622.

5. Pistritto $\mathrm{G}$ et al. Cell Death Differ 2002; 9: 995-1006.

6. Krajewska M et al. Clin Cancer Res 2005; 11: 5462-5471.

7. Seidelin JB, Nielsen OH. APMIS 2006; 114: 508-517.

8. Marastoni $S$ et al. Connect Tissue Res 2008; 49: 203-206.
} 